\title{
Sobre el (acabamiento del) estudio en la universidad ${ }^{1}$
}

About (finishing the) studio in the university

Jorge Larrosa ${ }^{i}$

Universidade de Barcelona

La ciudad, poblada por dos clases de personas, los que hacen negocios y sus víctimas, sólo es habitable, para el que aprende o estudia, de forma dolorosa, una forma que turba a cualquier naturaleza, con el tiempo la disturba y perturba y, muy a menudo, sólo de forma alevosa y mortal. Thomas Bernhard.

\section{Resumen}

El texto trata sobre la desaparición del estudio en la Universidad, sobre todo en las Facultades de Humanidades, poniéndolo en relación con el final de la mentalidad alfabética (Iván Illich), con la cultura del humanismo (Bernard Stiegler), pero también y sobre todo con la transformación del espacio, del tiempo, de las materialidades y de los sujetos que constituían la vieja universidad desde sus orígenes medievales hasta el triunfo completo del capitalismo cognitivo y de la mercantilización del conocimiento. Lo que está acabando con el estudio es la subordinación de la Universidad al dispositivo "profesionalización" (con lo que supone de subordinación al mercado de trabajo), al dispositivo "investigación" (completamente mercantilizado) y al dispositivo "aprendizaje" (completamente individualizado).

Palabras clave: estudio, universidad, lectura, libro.

\section{Abstract}

The text explores the disappearing of the studio in the university, especially in the Humanities, establishing relations with the end of the alphabetic mentality (Iván Illich), the culture of Humanism (Bernard Stiegler), as well as the transformation of space, time, materialities, and subjects who composed the old university since its medieval origins until the complete triumph of cognitive capitalism and knowledge commodification. What is finishing the studio is the subordination of the university to the mechanism of "professionalization" (with what it presupposes of subordination to the labor market), the mechanism of "investigation" (completely commodified) and the mechanism of "learning" (completely individualized).

\footnotetext{
${ }^{1}$ Conferencia pronunciada en la apertura del Congreso Iberoamenricano de Humanidades, Ciencias y Educación organizado por la Facultad de Humanidades de Criciúma (Santa Catarina, Brasil) en 2014.
}

Revista Digital do LAV - Santa Maria - vol. 9, n. 2, p. 114 - 132. - mai./ago. 2016 ISSN 1983 - 7348 http://dx.doi.org/10.5902/1983734823516 
Keywords: studio, university, reading, book.

Esta conferencia versará sobre el estudio en la Universidad, sobre todo en las viejas Humanidades o, en una expresión más hermosa, en los viejos estudios superiores de letras. Pero lo hará desde el final tanto de la Universidad como del estudio. Esa Universidad en la que aún se estudiaba está desapareciendo ante nuestros ojos. Vivimos el fin, o el acabamiento, tanto de la Universidad como del estudio. Lo que voy a hacer, entonces, es una especie de elogio fúnebre del estudio. Por eso, lo que voy a contarles, como los discursos fúnebres, no es ni verdad ni mentira. Es, simplemente, una ficción (entre otras), una manera de contar y de contarme algo de lo que creo que (nos) pasa a los que hemos hecho de la Universidad y del estudio, no sólo una carrera profesional, sino una forma de vida. Además, los elogios fúnebres clásicos, los epitáphioilogoi, no son sólo lamentos más o menos dramáticos, sino una mezcla bien compuesta de elogio (egkómion), exhortación (paraïnesis) y consuelo (paramuthía). "Los elogios fúnebres están construidos para alabar a los muertos, instruir a los jóvenes y aliviar a los viejos" (LORAUX, 2012, p. 70). Así que voy a alabar a dos muertos (uno de ellos se llama Universidad, pero ya no lo es, y otro se llama estudio, pero ya casi nadie sabe lo que significa), para ver si los jóvenes de la sala aprenden algo, y por si acaso a los viejos les sirve de algún consuelo.

Para dar un marco a lo que quiero decir, voy a comenzar por cuatro textos. Una conferencia del viejo e injustamente olvidado Iván Illich, una novela del escritor sudafricano y premio Nobel de literatura John Maxwell Coetzee, un libro del filósofo alemán Peter Sloterdijk, y una distinción de un filósofo y antropólogo de la técnica llamado Bernard Stiegler.

1.

Iván Illich pronunció en San Francisco, en 1986, una conferencia titulada "Por un estudio de la mentalidad alfabética". La conferencia está dedicada a proponer una perspectiva de análisis sobre un tipo de mentalidad, o de espacio mental, ligado al libro, que no se refiere sólo ni principalmente a la capacidad de leer y de escribir, sino que incluye toda una manera de entender el sujeto, sus actividades, sus relaciones consigo mismo y con el mundo. Esa mentalidad aparece en el siglo VII antes de nuestra era, con la generalización de la escritura, entre Sócrates, que no escribió una línea, y Platón, que ya fue un escritor, se extiende, se consolida y se impone a partir del siglo XII, con la constitución de las universidades europeas, se generaliza con la invención de la imprenta, en el siglo XV, y ahora está desapareciendo. Esa desaparición, dice Illich, tiene

Revista Digital do LAV - Santa Maria - vol. 9, n. 2, p. 114 - 132. - mai./ago. 2016 ISSN 1983 - 7348 http://dx.doi.org/10.5902/1983734823516 
que ver con la sustitución de la imagen del libro por la imagen de la computadora. No con la sustitución del libro por la computadora, sino la sustitución de la imagen mental ligada al libro, de la mentalidad alfabética, por la imagen mental ligada a la computadora, por la mentalidad comunicativa. Las palabras se convierten en unidades de información, el discurso se convierte en uso de la lengua, la conversación se convierte en comunicación oral, el texto se convierte en contenido, las capacidades humanas de hablar y escuchar, de leer y de escribir, se convierten en competencias comunicativas, el libro se convierte en soporte de información o en medio de comunicación, el viviente dotado de palabra, el zoónlogón echón de la definición aristotélica se convierte en una máquina comunicativa.

En un momento de esa conferencia, Illich dijo lo siguiente: "Siempre experimento un conflicto cuando rememoro un episodio que sucedió en Chicago en 1964, durante un seminario. Estábamos sentados alrededor de una mesa y un joven antropólogo se encontraba frente a mí. Llegamos a un momento crítico de lo que yo pensaba que era una conversación cuando me dijo: 'Illich, usted no logra conectarme, no se comunica conmigo'. Por primera vez en mi vida sentí que alguien se dirigía a mí, no como a una persona, sino como a un emisor-receptor. Tras un momento de desconcierto me sentí indignado. Un ser vivo, con quien creía conversar, había vivido nuestro diálogo como algo más general: una 'forma de comunicación humana' (...). Sólo tras haber estudiado, a lo largo de los años, la historia del espacio conceptual que surgió en la Grecia arcaica, capté hasta qué punto la computadora en cuanto metáfora exilia a los que la aceptan, los vuelve ajenos al espacio del espíritu alfabético. Comencé entonces una reflexión sobre la emergencia de un nuevo espacio mental cuyos axiomas generadores ya no son la codificación de la voz humana por medio del alfabeto, sino el poder de almacenar y manipular bits de información"n.

Quisiera destacar tres cosas de esta cita. Primero, el modo como Illich se sorprende y se indigna (se siente insultado) por algo que en esta época ya está completamente naturalizado: la reducción del lenguaje humano a medio de comunicación. Illich se siente mal porque alguien le trata no como a una persona que conversa, sino como a un sujeto que comunica. Segundo, la oposición entre conversar y comunicar: los seres humanos

\footnotetext{
${ }^{2}$ No capítulo "Por un estudio de la mentalidad alfabética", en Obras Reunidas II (2008) Illich relata otra vez esa misma historia con algunas variaciones: "Recuerdo cuando me topé por primera vez con el concepto de comunicación. Fue en la Universidad de Chicago, quizá hace veinte años, durante un encuentro con estudiosos de las ciencias sociales. Entonces un joven se sentó y me dijo: 'Illich, no se haga ilusiones, no consigo leerle. Usted no comunica conmigo, no capto su mensaje'. Mi respuesta inmediata fue: 'señor, no tengo ninguna intención de ser un micrófono'. Creí que quería ofenderme, identificándome con una emisora de radio. iSólo más tarde he entendido que probablemente acababa de ver su Departamento de Inglés rebautizado como Departamento de Comunicaciones! Conté esa historia en la Universidad de Friburgo (...). Ninguno de los jóvenes entendió lo que estaba diciendo. Daban por sentado que nos estábamos intercambiando informaciones" (CALEY, 2013, p. 57-58).
}

Revista Digital do LAV - Santa Maria - vol. 9, n. 2, p. 114 - 132. - mai./ago. 2016 ISSN 1983 - 7348 http://dx.doi.org/10.5902/1983734823516 
conversan, las máquinas comunican. Los seres humanos hablan y escuchan, son hablantes y escuchantes, escritores y lectores, pero no codificadores-descodificadores o emisores-receptores. Entender el lenguaje como la variante humana de un intercambio comunicativo que tiene lugar también entre las abejas, los delfines, las bacterias y las computadoras es degradarlo y, sobre todo, hacerlo susceptible de cálculo mercantil y de manipulación técnica. Es también ahormarlo según los ideales comunicativos, es decir, la eficacia y la transparencia. Tercero, la oposición entre la "mentalidad alfabética", aquella según la cual la escritura es la transcripción de la voz humana, aquella según la cual leer es, de algún modo, un escuchar... y la metáfora de la computadora, esa según la cual la escritura es un medio de comunicación, es decir, un mero soporte de unidades de información, de lo que hoy se llamarían "contenidos". Esa metáfora según la cual leer y escribir no son otra cosa que prácticas de codificación y decodificación, prácticas o instrumentos encaminados a procesar información.

Las últimas frases de la conferencia dicen así: "Mi mundo es el de las letras. No me siento en casa más que en la isla del alfabeto. Esta isla la comparto con mucha gente que no sabe leer ni escribir, pero cuya mentalidad es fundamentalmente alfabética, como la mía. Y ellos están tan amenazados como yo por la traición de aquellos que, entre los clérigos, desintegran las palabras del libro en un simple código de comunicación" ${ }^{\prime 3}$. El mundo de las letras es una isla, la isla del alfabeto, y los habitantes de esa isla (que no está compuesta sólo, dice Illich, por los que saben leer y escribir) han sido traicionados por aquellos mismos que decían defenderla. Y en la palabra "traición", en el gesto de llamar traidores a los que desintegran las palabras del libro en un simple código de comunicación, a los que ya no leen sino comunican, resuena el título del libro de Julien Benda, ese otro antimoderno o reaccionario de izquierda, que en 1927 escribió La traición de los clérigos, La trahison des clercs, a veces traducido como La traición de los intelectuales, en el que denunciaba la manera como la Universidad se había puesto al servicio de las ideologías que estaban fundamentando los nuevos estados totalitarios y los nuevos estados coloniales, es decir, la sumisión de la Universidad al estado. Pero vamos a dejar, de momento, esa cuestión de la sumisión de la Universidad a los diversos poderes, a la iglesia, al estado, quizá en esta época al nuevo capitalismo globalizado, ese

\footnotetext{
${ }^{3}$ En otro lugar: "El texto libresco es mi hogar, y es a la comunidad de lectores librescos a quien me refiero cuando digo 'nosotros'. Este hogar está ahora tan pasado de moda como la casa en la que nací, cuando las bombillas empezaban lentamente a reemplazar a las velas. En cada computadora hay una apisonadora acechando con la promesa de abrir nuevas autopistas para los datos, las sustituciones, las inversiones y la impresión instantánea. Un nuevo tipo de texto moldea la mentalidad de mis alumnos: el texto que sale de la impresora no tiene ancla, no puede pretender ser una metáfora ni un original de la mano del autor. Como las señales de una goleta fantasma, sus fibras digitales forman moldes de imprenta arbitrarios en la pantalla, fantasmas que aparecen para desvanecerse después. Cada vez menos gente se acerca al libro como a un puerto de significado. Sin duda aún transmite a algunos admiración y alegría, perplejidad y amargo pesar; pero me temo que, para la mayoría, su legitimidad consiste en ser poco más que una metáfora apuntando hacia la información" (ILLICH, 2002, p. 156).
}

Revista Digital do LAV - Santa Maria - vol. 9, n. 2, p. 114 - 132. - mai./ago. 2016 ISSN 1983 - 7348 http://dx.doi.org/10.5902/1983734823516 
que lo convierte todo, también el conocimiento, también a los profesores y a los estudiantes, en servidores de la producción y de la mercancía, y vamos a seguir con eso de la reducción del lenguaje a medio de comunicación.

2.

La misma transición entre dos mentalidades que cuenta Illich, la vive con una mezcla de pesimismo y resignación otro clérigo de la época de la alfabetización, David Lurie, el protagonista de la novela "Desgracia" de J.M. Coetzee. El protagonista de la novela, el tal David Lurie, "Se gana la vida en la Universidad Técnica de Ciudad del Cabo, antes Colegio Universitario de Ciudad del Cabo. Antiguo profesor de Lenguas Modernas, desde que se fusionaron los Departamentos de Lenguas Clásicas y Modernas por la gran reforma llevada a cabo años antes, es profesor adjunto de Comunicaciones. Como el resto del personal que ha pasado por la reforma, se le permite impartir una asignatura especializada por cada curso, sin tener en cuenta el número de alumnos matriculados, pues se considera positivo para la moral del personal. Este año imparte un curso sobre los poetas románticos. Durante el resto de su tiempo da clase de Comunicaciones 101, "Fundamentos de comunicación", y de Comunicaciones 102, "Conocimientos avanzados de comunicación". Si bien diariamente dedica horas y horas a su nueva disciplina, la premisa elemental de ésta, tal como queda enunciada en el manual de Comunicaciones 101, se le antoja absurda: "La sociedad humana ha creado el lenguaje con la finalidad de que podamos comunicarnos unos a otros nuestros pensamientos, sentimientos e intenciones". Su opinión, por más que no la airee, es que el origen del habla radica en la canción, en la necesidad de llenar por medio del sonido la inmensidad y el vacío del alma humana. Nunca ha sido ni se ha sentido muy profesor. En esta institución del saber tan cambiada y, a su juicio, emasculada, está más fuera de lugar que nunca. Claro que, a esos mismos efectos, también lo están otros colegas de los viejos tiempos, lastrados por una educación de todo punto inapropiada para afrontar las tareas que hoy se les exige que desempeñen. Son clérigos en una época posterior a la religión. Como no tiene ningún respeto por las materias que imparte, no causa ninguna impresión en sus alumnos. Cuando les habla, lo miran sin verlo. La indiferencia de todos ellos le indigna más de lo que estaría dispuesto a reconocer. No obstante, cumple al pie de la letra las obligaciones que tiene para con ellos, con sus padres, con el estado".

Lo que ha cambiado, parece decir Coetzee, es la idea del lenguaje. Y eso ha convertido a los viejos profesores formados en la mentalidad alfabética en clérigos de una época posterior a la religión. O de una época que está cambiando de dioses. Son otros los dioses y son otros sus representantes.

3.

Revista Digital do LAV - Santa Maria - vol. 9, n. 2, p. 114 - 132. - mai./ago. 2016 ISSN 1983 - 7348 http://dx.doi.org/10.5902/1983734823516 
Peter Sloterdijk comienza uno de sus libros más polémicos con estas palabras: "Como dijo una vez el poeta Jean Paul, los libros son voluminosas cartas para los amigos. Con esta frase estaba llamando por su nombre, tersa y quintaesencialmente, a lo que constituye la esencia y función del humanismo: humanismo es telecomunicación fundadora de amistades que se realiza en el medio del lenguaje escrito". Y un poco más adelante: "es claro que el remitente de este género de cartas amistosas lanza al mundo sus escritos sin conocer a los destinatarios (...); no deja de ser consciente de que su envío sobrepasa el alcance previsto y puede dar ocasión de que surja un número indeterminado de relaciones amistosas con lectores anónimos y, a menudo, todavía por nacer (...). El texto escrito no sólo construye un puente telecomunicativo entre amigos consolidados que en el momento del envío viven espacialmente distantes uno del otro (...), sino que lanza una seducción a lo lejos (...), con el fin de dejar al descubierto como tal a ese desconocido amigo y motivarlo para que entre en el círculo. De hecho, el lector que se expone a los efectos de la carta voluminosa puede entender el libro como una invitación, y si tan solo se deja abrigar al calor de la lectura, es seguro que se personará en el círculo de los aludidos para allí dar fe de que ha recibido el envío" (SLOTERDIJK, 2000, p. 19-20).

En este fragmento, la cultura literaria humanista se presenta como una especie de sociedad letrada, fundada en la amistad y dilatada tanto en el tiempo como en el espacio, en el que los emisores saben de la imprevisibilidad de sus receptores y, aun así, se embarcan en la tarea de escribir concienzudas cartas dirigidas a amigos no identificados. Pero después de ese comienzo, Sloterkijk arremete contra ese fantasma comunitario de la sociedad literaria, contra ese sueño de la secta o del club de los amigos que se intercambian cartas y que, en su proyecto expansivo y universalizante, se proyecta como una norma para toda la sociedad. Sloterdijk declara el fin de la época del Humanismo y, por tanto, de la época dorada de la Pedagogía, de esa época en la que los intérpretes autorizados, los guardianes de los libros y de las bibliotecas, los maestros de lectura, no sólo presumían de un conocimiento privilegiado de cuáles eran las cartas fundadoras de amistad, de comunidad, sino que se arrogaban la misión de incorporar a las nuevas generaciones en el círculo de los intercambios epistolares. En esa época remota y desaparecida, la comunidad humana ideal se concebía como una especie de comunidad de escritores y de lectores, como una especie de sociedad literaria, con cuyo modelo se construyeron tanto los estados nacionales como, en el límite, la idea misma de humanidad que subyace a eso que algunos todavía llaman, o llamamos, "Humanidades". 4.

Revista Digital do LAV - Santa Maria - vol. 9, n. 2, p. 114 - 132. - mai./ago. 2016 ISSN 1983 - 7348 http://dx.doi.org/10.5902/1983734823516 
Bernard Stiegler tiene un libro en el que habla de la escuela en general, y de la Universidad en particular, como de dispositivos atencionales (STIEGLER, 2008). Toda educación, dice Stiegler, no es otra cosa que una serie de procedimientos dirigidos a capturar la atención, a orientarla, a disciplinarla, a dirigirla y, en definitiva, a formarla. Para Stiegler la educación se produce siempre, necesariamente, conectando a los individuos, a los recién llegados al mundo si seguimos la terminología arendtiana, a una serie de psicotecnologías (tecnologías del alma) o de noo-tecnologías (tecnologías del espíritu) que son constitutivas del mundo humano.

En ese contexto, Stiegler traza una distinción entre la época de la Bildung, de la formación, en que los dispositivos fundamentales de formación de la atención eran la lectura y la escritura (la época de la alfabetización, de la "mentalidad alfabética" de Illich, la época en que el ideal educativo era constituir una sociedad plenamente alfabetizada, una sociedad de lectores y de escritores) y esta época nuestra en que la atención es capturada por las nuevas tecnologías, por las así llamadas Tecnologías de la Información y de la Comunicación. Una época, además, que se caracteriza por las patologías atencionales, por los diversos síndromes del déficit o del desorden de la atención que se diagnostican masivamente. Podríamos decir, siguiendo a Stiegler, que, en la época de la Bildung, se trataba de conectar a los individuos al mundo de la letra, porque la letra es lo que constituía, esencialmente, el mundo, el mundo propio y el mundo común de la gente formada, de la gente cultivada, de la gente entrenada en las artes de leer y de escribir, en las formas críticas de la cultura. Podríamos decir que en la época de la Bildung leer y escribir eran las formas fundamentales del estar conectado. Y que la pretensión, o el ideal, de los aparatos educativos era universalizar esa conexión, que no quedara nadie fuera del mundo alfabetizado. $Y$ eso es lo que ocurre también ahora con las nuevas tecnologías, que no aceptan el afuera, que aspiran a vincular a todos, que constituyen también un ideal totalitario y totalizador de conexión.

Pero lo que el libro de Stiegler da a pensar es la "forma de la atención" que se pone en juego en cada caso. Escribe Stiegler: "Público, en la época de la Ilustración, en la época de la Bildung (en tanto que Bildung incluye tanto Kultur como Aufklärung) significa 'público que lee', es decir, público capaz de acceder a esa forma específica de la atención que el libro captura (...). Son los escritores y los lectores los que, leyendo y escribiendo, acceden a la forma crítica de la atención" (STIEGLER, 2008, p. 48-49). Además, convendrán conmigo que la lectura y la escritura constituyen también, históricamente, una forma muy específica de producir tanto la soledad (lo que he llamado lectura solitaria) como la compañía (lo que he llamado lectura pública). La atención crítica no es otra cosa que establecer, en relación a la letra, un tipo particular de diálogo, tanto el

Revista Digital do LAV - Santa Maria - vol. 9, n. 2, p. 114 - 132. - mai./ago. 2016 ISSN 1983 - 7348 http://dx.doi.org/10.5902/1983734823516 
diálogo del alma consigo misma o el diálogo del sujeto consigo mismo (como otro), como el diálogo del sujeto con los otros. Y eso sin descargarse de la responsabilidad de hablar por sí mismo, de leer por sí mismo, de escribir por sí mismo, de pensar por sí mismo. En la lectura y la escritura, el uso público y en público de la propia razón, el modo como cada uno se constituye en crítico de lo que lee y, a la vez, se expone a la crítica en lo que escribe, está fundado en la lectura individual, es decir, en la soledad y en el silencio, y, sobre todo, está orientado al desarrollo del pensamiento individual.

Porque la lectura y la escritura, lo que Illich llamaba "la mentalidad alfabética", lo que Stiegler Ilama "la forma letrada de la atención", abre para el sujeto no sólo un tipo particular de espacio público, sino también un tipo muy especial de soledad. La invención de la literatura, del mundo del texto escrito, del mundo de la letra, es inseparable de la constitución de algo común, pero también, y quizá aún más importante, de nuevas formas de soledad y de silencio, de nuevas formas, por utilizar una palabra antigua, de recogimiento. El estudioso, el hombre de letras, es un ser que se comunica, que se conecta, diríamos nosotros, a través de la letra, pero es también, esencialmente, un ser que se aísla, que se separa, que se desconecta. Por eso la lectura y la escritura son, también, caminos hacia la interioridad.

De hecho, en la era de la alfabetización esa extraña dialéctica entre conexión y desconexión es la que separa lo que Stiegler llama "la forma dogmática" y "la forma crítica" de la atención. De hecho, el lector y el escritor dogmáticos son los que no se desconectan, los que no son capaces de abrir en sí mismos ese espacio de silencio y soledad que hace posible el pensar por sí mismo, el leer por sí mismo, el escribir por sí mismo.

Y el final de la era de la Bildung, de la forma letrada y crítica de la atención, tiene que ver, desde luego, con la sustitución de la lectura y la escritura por la información y la comunicación, pero tiene que ver, sobre todo, con la cancelación de un espacio público para la lectura y la escritura y, por otro lado, con la imposibilidad de desconectarse, es decir, con la cancelación de la soledad del leer y el escribir.

5 .

Ivan Illich, David Lurie, Peter Sloterdijk o Bernard Stiegler están viviendo el fin de la lectura en la Universidad, o el fin de la Universidad lectora, la disolución de una forma pedagógica que se ha mantenido prácticamente inalterada durante siglos aunque haya ido cambiando su función. No se trata tanto, o no sólo, de que la Universidad se esté poniendo al servicio de las nuevas formas del capitalismo, de lo que ha venido en llamarse el "capitalismo cognitivo", o el "semio-capitalismo", no se trata tanto, o no sólo, de que se estén redefiniendo los objetivos, o las funciones, de la Universidad, sino

Revista Digital do LAV - Santa Maria - vol. 9, n. 2, p. 114 - 132. - mai./ago. 2016 ISSN 1983 - 7348 http://dx.doi.org/10.5902/1983734823516 
también, y sobre todo, de que una determinada forma, un determinado dispositivo, una determinada manera material de disponer espacios, tiempos, cuerpos, relaciones, objetos, lenguajes y maneras de hacer, está desapareciendo ante sus ojos. Por lo tanto, a partir de ahora, no voy a hablar apenas de las funciones de la Universidad sino que voy a hablar sobre todo de su forma, de su estructura formal y material, de sus procedimientos, de sus rutinas, de sus rituales, de sus tecnologías, de sus modos de hacer.

Uno de los lemas de los indignados era "le dicen democracia y no lo es". Y creo que vivimos en una época en que permanecen los nombres, pero ya no existe aquello que nombraban. Así que me atrevería a decir que "le dicen estudio y no lo es", o "le dicen Universidad y no lo es".

Para comenzar me gustaría arriesgar la definición de Universidad de Alfonso X el Sabio, rey de Castilla y León en el siglo XIII, en Las Partidas, uno de los textos jurídicos medievales más importantes de Europa. Además, no fueron escritas en latín, sino en castellano (aún no podía hablarse de español), y fueron traducidas muy pronto al catalán, al gallego, al portugués, al francés y al inglés. La definición no es de Universidad, sino de Estudio, teniendo en cuenta que las primeras universidades se derivaron de los Estudios Generales (Studia Generalia) monásticos o de las escuelas catedralicias. En Las Partidas se usa indistintamente el término Estudio, el término Universidad o, incluso, la expresión Universidad del Estudio. Así, en Las Partidas, "Estudio es ayuntamiento de maestros y escolares, que es hecho en algún lugar, con voluntad y con entendimiento de aprender los saberes".

Sólo por seguir la pista del Rey Sabio, creo que deberíamos repensar qué quiere decir hoy, para nosotros, "maestro", si es que aún hay maestros, qué quiere decir "escolar", si es que aún hay escolares, qué quiere decir "ayuntamiento", si es que maestros y escolares aún se juntan, aún hacen algo juntos, qué quiere decir "algún lugar", si es que la Universidad aún está ligada a un tipo particular de lugar, de espacio, y qué quiere decir "aprender los saberes", y cómo, y en relación a qué, se aprenden.

En cualquier caso, en la definición del Rey Sabio el Estudio, o la Universidad, estaba definido por un lugar, por unos sujetos (el maestro y los escolares), y por un objeto o una materialidad, los saberes, que se encarnaba en el libro de texto. $Y$ de hecho, la regulación del buen funcionamiento de la Universidad, en Las Partidas, consiste, sobre todo, en garantizar las condiciones del lugar, las obligaciones (pero también las libertades) de los maestros y de los escolares (unas libertades que hoy nos parecerían casi imposibles, de hecho, la Universidad medieval, durante muchos años, no estuvo

Revista Digital do LAV - Santa Maria - vol. 9, n. 2, p. 114 - 132. - mai./ago. 2016 ISSN 1983 - 7348 http://dx.doi.org/10.5902/1983734823516 
sometida a ningún poder, ni civil ni religioso), y la fiabilidad de los libros (a través, por ejemplo, de una serie de medidas que castigaban el fraude en la edición o en la copia). 6.

Vamos primero con los espacios (y los tiempos) de la Universidad. Porque en ellos están los espacios y los tiempos del estudio.

Lo primero que habría que decir es que la Universidad se constituye por una separación nítida de tiempos y espacios. En primer lugar, por la creación de un tiempo otro, de una especie de tiempo fuera del tiempo, de un tiempo libre. De hecho, la palabra escuela viene del griego scholé que significa, literalmente, tiempo libre. La escuela sería el lugar del tiempo libre. Y todavía hoy, en algunos países, los universitarios siguen llamándose scholars, es decir, personas que habitan la escuela, pero sobre todo personas que disponen de tiempo libre. $Y$ tiempo libre quiere decir tiempo liberado del trabajo, tiempo no productivo, pero también tiempo no contado, no contabilizado, no limitado, no determinado, indefinido. La Universidad, desde este punto de vista, sería ese lugar en el que a las personas se les da tiempo, o ese lugar en el que las personas pueden tomarse tiempo... para estudiar.

Además de un tiempo particular, de un tiempo libre, para estudiar también hace falta un espacio particular, un espacio separado, al mismo tiempo en el mundo y fuera del mundo. Hay un extraño texto de Hannah Arendt que se titula "¿Dónde estamos cuando pensamos?" (ARENDT, 1984), en el que desarrolla la idea de que el pensamiento supone introducirse en otro espacio y en otro tiempo. O, mejor, que el pensamiento supone la suspensión del espacio ordinario (ese que está definido por una serie de lugares, y en el que hay un lugar para cada cosa y cada cosa tiene su lugar) y del tiempo ordinario (tanto el tiempo cronométrico, medido, cuantificado; como el tiempo productivo organizado según un antes y un después y orientado prácticamente al futuro; y como el tiempo de la necesidad, ese tiempo de las urgencias en el que se está siempre ocupado). Ese estar fuera de lugar, dice Hannah Arendt, hace del yo pensante una especie de apátrida, un habitante de "ninguna parte", y un habitante también de un tiempo fuera del tiempo, de una especie de "ningún tiempo" cuya condición de posibilidad sería el tiempo libre. En sus propias palabras: "los filósofos aman este 'en ninguna parte' como si fuera un país (philochòrein), y desean renunciar a cualquier otra actividad por el solo placer de estar scholazein (ociosos, como hoy diríamos)" (ARENDT, 1984, p. 230). Y yo creo que de los estudiosos podría decirse lo mismo, que aman estar en ninguna parte y disfrutan de un tiempo que no se cuenta.

Y Peter Sloterdijk, en un libro dedicado a analizar la emergencia y la decadencia del hombre teórico, de la actividad contemplativa, también se refiere a ciertos estados

Revista Digital do LAV - Santa Maria - vol. 9, n. 2, p. 114 - 132. - mai./ago. 2016 ISSN 1983 - 7348 http://dx.doi.org/10.5902/1983734823516 
ausentes del filósofo que "permanece inmóvil ante nosotros pero está muy lejos", lo que hace que "desde hace más de dos milenios y medio una parte pequeña, pero no inesencial, de la población de nuestro hemisferio está siempre con el pensamiento en otra parte. Edificios de academias, escuelas, monasterios, iglesias y recintos de soledad muestran cómo ese en-otra-parte se articula arquitectónicamente". Y, un poco más adelante, "Platón recondujo la retirada de la ciudad a la ciudad misma e instauró con ese gesto una diferencia político-topológica de grandes consecuencias. Por utilizar la terminología de Michel Foucault, el asentamiento de la Academia en la ciudad significa una heterotopía. Esta expresión designa un lugar delimitado que, aun siendo cierto que se incluye en el entorno normal u ortópico de la polis, está sujeto a sus propias leyes, chocantes e incluso incomprensibles para la ciudad" (SLOTERDIJK, 2013, p. 47-48).

Además, esa especie de espacio fuera del espacio que hace del filósofo un extranjero o un exiliado respecto a los espacios de la polis, requiere, también para Sloterdijk, de un tiempo especial: "la institución del período escolar ha contribuido a la producción del ser humano capaz de epojé, dado que la estancia en la escuela se entendió como liberación de los demás asuntos y obligaciones. De ahí el parentesco de sentido, comentado a menudo, de las palabras ocio, scholé, y centro de formación, schola"(SLOTERDIJK, 2013, p. 79-80). A los profesores, en algunos países, aún se les llama "académicos", como si vivieran en uno de esos lugares que, según Sloterdijk, articulan arquitectónicamente ese en-otra-parte que está dentro de la ciudad pero que no pertenece a ella.

Habría que decir, además, que ese en-otra-parte de la Universidad se constituye como un lugar muy específico, con una forma arquitectónica y una materialidad muy concreta, pero también se constituye, al mismo tiempo, como un lugar ubicuo, como un lugar que puede estar en cualquier parte. Los maestros tienen el derecho a enseñar en cualquier universidad (licentia ubique docendi) y los estudiantes también pueden asistir, libremente, a las lecciones de cualquier maestro impartidas en cualquier universidad. De hecho, la universidad medieval supone la aparición de una nueva figura del nomadismo y de la vida errante, las figuras gemelas del maestro itinerante y del estudiante viajero que atraviesan, de Universidad en Universidad, una Europa desgarrada por las guerras de religión y por los sangrientos conflictos de fronteras entre las naciones emergentes. Además, a esa libre circulación de maestros y estudiantes debe añadirse también la libre circulación de los libros. La Universidad, por tanto, es un lugar, pero un lugar ubicuo, extraterritorial, un lugar que no está anclado a ningún lugar concreto $(\mathrm{y}$, por tanto, a una cultura particular, a una nación concreta, a un conocimiento local, a un saber contextual, etc.), un lugar que puede estar en cualquier lugar.

Revista Digital do LAV - Santa Maria - vol. 9, n. 2, p. 114 - 132. - mai./ago. 2016 ISSN 1983 - 7348 http://dx.doi.org/10.5902/1983734823516 
La forma espacial de esa Universidad antigua, arcaica, casi intemporal de tan vieja, de ese lugar que no es, estrictamente, un lugar, porque es, de alguna manera, heterotópico, y porque, además, puede situarse en cualquier lugar, está constituida por un aula conectada a una biblioteca. La Universidad fue, durante siglos, una sala de clases, una sala de aula (y la palabra "aula" significa tanto en griego como en latín, un patio cercado en el que se hacían ceremonias y, por extensión, un patio abierto en los palacios, de ahí lo de consejero áulico, es decir, sin un lugar o una posición definida en la estructura del Estado), en la que se reúnen, de cuerpo presente, profesores y alumnos, y en la que se reúnen para leer, para leer en común, para ejercitarse en la lección, en la lectio, en la lectura pública y en público de un texto, de un libro de texto, y, a través de eso, para iniciarse en ese infinito borgiano que es, o que era, la biblioteca.

La Universidad es un vaivén entre el aula (que es un lugar de ceremonias, el lugar de la lectio, el lugar de la ceremonia pública de la lectura) y la biblioteca (que es un depósito de libros y también un lugar de lectura, pero de lectura privada, solitaria, de lectura, podríamos decir, no ceremonial). Y es esa lectura no ceremonial la que se llamará, más adelante, "estudio". De modo que la tarea de los maestros será impartir lecciones, leccionar, leer en público (todavía hay una categoría de profesores que se llama "lector"), y la tarea de los estudiantes será estudiar, es decir, ejercitarse en la lectura, demorarse a solas en la lectura.

Podríamos decir que la función de los maestros es una especie de doble transporte. Por un lado transportan libros de la biblioteca a la sala de aula. Y por otro lado transportan a los estudiantes de la sala de aula a la biblioteca. Un doble transporte que es una doble entrega: entregar los libros a los estudiantes, y entregar a los estudiantes a los libros, es decir, entregarlos al estudio.

7.

Vamos a hablar ahora de los libros. De los libros en la Universidad, y de los libros como materialidad del estudio.

El aula se constituye como un espacio público (no un espacio para actividades individuales y/o colectivas, sino para actividades públicas, para hacer cosas públicamente y en público). Y ese espacio público se articula alrededor de una materia de estudio común ( $y$ aquí común no significa algo que se comunica, sino algo que es de todos en general y de nadie en particular). Además, la materialidad de esa materia común, de esa materia comunizada, de esa materia que se hace pública en la lectio, y que se ejercita en el estudio, es el libro de texto. $Y$ el libro de texto es un libro que ya no es la huella de una revelación divina, ni siquiera el registro de una voz, sino la materialización del pensamiento.

Revista Digital do LAV - Santa Maria - vol. 9, n. 2, p. 114 - 132. - mai./ago. 2016 ISSN 1983 - 7348 http://dx.doi.org/10.5902/1983734823516 
El libro de texto, que es el gran invento de la Universidad, es un objeto fundamentalmente óptico (y por tanto legible y ya no audible) que está disponible para el estudio en tanto que se ofrece para la interpretación y el comentario. El libro de texto se constituye por la sustitución del texto audible (que pide obediencia... obedecer viene del latín ob-audire, escuchar) por el texto legible, que pide interpretación crítica. Pero al mismo tiempo, en tanto que ese texto legible es leído públicamente, se convierte también en un texto audible, pero audible en segundo grado, es decir, parafraseable, comentable, interrumpible, cuestionable. Ya no un texto sagrado, aunque conserva su autoridad y su prestigio, sino un texto que se profana en tanto que se lo lee, se lo comenta, se lo interrumpe, se lo cita, se lo subraya, se lo anota, se lo traduce, se lo parafrasea, se lo hace resonar con otros textos, se le hacen preguntas, es decir, en tanto que se lo somete a todas las prácticas desacralizadoras propias de la lectura escolástica. La lectio opera dando al texto el poder de provocar el pensamiento, tanto de los estudiantes como de los profesores. Pero de un pensamiento, insisto, que debe ser elaborado y sostenido públicamente, y en público.

Por eso la Universidad hace posible, esencialmente, tanto el pensamiento público como la publicación del pensamiento. Al texto se le hacen preguntas públicamente y, sobre todo, se le hace hablar, también públicamente, desde distintos puntos de vista que no son complementarios sino rivales (de ahí que los ejercicios fundamentales en la sala de aula sean la questio y la disputatio). Pero, fundamentalmente, al texto se lo comenta.

8.

En un texto muy breve que se titula "Idea del estudio", Giorgio Agamben empieza diciendo: "Talmud significa estudio" (AGAMBERN, 2014, p. 62). La Torá es la doctrina y, como ustedes saben, el Talmud está compuesto por los comentarios a la doctrina hechos, a lo largo de siglos, por una serie de maestros o de rabíes. Por eso, si Talmud significa estudio, nosotros podríamos decir que estudio significa comentario. Y, como saben, el comentario de texto es el otro gran ejercicio de la Universidad. En la Universidad se lee y se comenta o, si quieren, se lee y se estudia. Pero comentario significa, esencialmente, pluralidad. La estructura de una página del Talmud es significativa a este respecto. En el centro, un fragmento de la doctrina, de la Torá, y a su alrededor, los comentarios. Como si los comentarios rodearan el texto, sin cubrirlo nunca, sin llegar nunca a él, abriéndolo a distintas lecturas. El poeta judío Edmond Jabès dice algo parecido utilizando homofónicamente la palabra francesa "commentaire". El verso sería así: "commentaire: comment-taire, comment taire un signifié fixé, donné d'avance". El comentario es el acallamiento del significado fijo, dado de antemano, y el surgimiento, en ese silenciamiento, de una multitud de lecturas. Además, en las lenguas latinas, la palabra

Revista Digital do LAV - Santa Maria - vol. 9, n. 2, p. 114 - 132. - mai./ago. 2016 ISSN 1983 - 7348 http://dx.doi.org/10.5902/1983734823516 
comentario tiene el cum del común. Por tanto, el comentario define al texto no sólo como plural sino también como lo común, como lo que está en el medio, como lo que es de todos y está entre todos, y al mismo tiempo como lo que diferencia, lo que pluraliza, como lo que hace de la lectura un acontecimiento de la pluralidad y de la diferencia, como lo que le da al texto, podríamos decir, parafraseando a Jean Luc Nancy, un ser singular-plural.

Antes me referí a la definición de Estudio como "Ayuntamiento de maestros y escolares". Tal vez ahora estemos en condiciones de volver sobre qué tipo de "ayuntamiento" es ese. Qué tipo de comunidad, de com-munitas, constituyen los maestros y los escolares, qué tipo de relación colectiva mantienen con un munus que no se parte ni se reparte sino que se comparte. Podríamos decir que, en la Universidad, en el estudio, lo que hace comunidad, el munus que la constituye, no es otra cosa que el texto y la relación con el texto. Por eso la lectio, la lectura y el comentario público de un texto, constituye un collegium o un colloquium, un leer juntos y un pensar juntos (públicamente y en público) alrededor de un texto común. Y eso, ese leer y pensar públicamente y en público, tienen como función, según la definición del Rey Sabio, aprender los saberes.

Por eso, el saber no es una herramienta, un medio para otra cosa, un instrumento, sino un fin en sí mismo. Y el estudio sería algo así como lo que Agamben llama un medio puro, un medio sin finalidad exterior, una actividad puramente autotélica, es decir, una actividad que tiene en sí misma su propia finalidad.

Por eso, tanto la lectio como el studium deben pensarse en la lógica del ejercicio. La palabra latina exercitium, como saben, traduce la palabra griega ascesis. El maestro y los estudiantes (en tanto que lectores y estudiantes y estudiosos) son seres ejercitantes, seres entregados al ejercicio, a la ascesis. A un ejercicio y a una ascesis que lo son en la lectura y en el estudio, pero cuyos efectos están en el pensamiento.

9.

He hablado del tiempo del estudio (un tiempo libre, no productivo, indefinido). He hablado también del espacio del estudio (un espacio público). He hablado también de la materialidad del estudio (la lectio, el libro de texto, el comentario). He hablado también del estudio como de un ejercicio puro, no sometido a ninguna finalidad exterior. Vamos ahora con los sujetos del estudio, con los maestros y los estudiantes.

He dicho antes que la Universidad se define como universitas magistrorum et scholarium o como universitas studii. $Y$ añadiré ahora que la Universidad surge precisamente de su separación de las escuelas catedralicias y de las escuelas monásticas en las que se origina. En la Universidad, el maestro ya no es un guía o un director espiritual o un iniciador en la religión, sino que es maestro de un saber. $Y$ de un saber, además, que no

Revista Digital do LAV - Santa Maria - vol. 9, n. 2, p. 114 - 132. - mai./ago. 2016 ISSN 1983 - 7348 http://dx.doi.org/10.5902/1983734823516 
es técnico o práctico, como el de los maestros artesanos, los maestros zapateros o los maestros pedreros, los maestros de los gremios medievales, sino que es un saber que no está ligado a ningún tipo de productividad concreta. El maestro, en la Universidad, no está como el propietario de un saber iniciático (como el de los conventos) ni de un saber técnico (como el de los gremios). Y en la Universidad, la figura del estudiante constituye también una identidad nueva en tanto que se separa, por un lado, de la figura del aprendiz, ligada a los gremios y al aprendizaje de una profesión generalmente ligada a la artesanía y, por otro lado, de la figura del discípulo, ligada al monasterio y, por tanto, a la iniciación religiosa. Uno se constituye en aprendiz cuando aprende habilidades prácticas o técnicas. Uno se constituye en discípulo cuando se convierte en seguidor de un maestro espiritual. En los talleres de los artesanos, que son lugares de aprendizaje profesional, hay aprendices, y en los monasterios, que son lugares de iniciación religiosa, hay discípulos. Pero en la Universidad no hay aprendices ni discípulos, como tampoco hay maestros en una técnica o guías espirituales. En la Universidad hay maestros y escolares, estudiosos y estudiantes, es decir, personas que tienen tiempo libre (scholè) para el estudio. $Y$ personas cuya tarea no es de naturaleza privada, como en el caso de los aprendices y los discípulos, no es una aventura personal, particular, ligada a un interés propio, sea a un interés productivo o un interés religioso, sino que es una tarea pública. Tanto los profesores como los estudiantes son figuras públicas. Como dicen Masschelein y Maartens, "los estudiantes y los profesores no tienen intereses específicos sino que, como parte de una esfera pública, están interesados y ligados a un mundo más allá de la cultura nacional, de los órdenes de la burocracia y de la lógica institucional". (MASSCHELEIN; SIMONS, 2011, p. 166). El estudio, la lectura, el comentario, son, en la Universidad, tareas públicas. El texto no es objeto de una apropiación privada, sino que es hecho público. Y lo que caracteriza al pensamiento no es su carácter de propio, el ser el pensamiento propio de alguien, sino el hecho de ser formulado públicamente. Estudiar, en la Universidad, es leer y pensar en presencia de otros.

Los profesores universitarios no son sabios, ni clérigos, ni funcionarios del estado, ni servidores de la iglesia. Son maestros, es decir, personas con una maestría especial, cuya autoridad no se deriva ni del carácter técnico, o práctico, o utilitario de su saber, ni tampoco de su garantía religiosa. Su autoridad se deriva de su estudio, de su condición de estudiosos, y de su capacidad de mostrar públicamente su estudio, es decir, su lectura. Los maestros no son otra cosa que lectores que dan a leer, estudiosos que hacen estudiar. No son productores sino scholars, escolares, personas que disponen de scholè, de tiempo libre, para el estudio. $Y$ que usan ese tiempo libre también para ejercer como profesores, como personas que leen públicamente y que dan a leer públicamente, como

Revista Digital do LAV - Santa Maria - vol. 9, n. 2, p. 114 - 132. - mai./ago. 2016 ISSN 1983 - 7348 http://dx.doi.org/10.5902/1983734823516 
personas cuya profesión es leccionar, dar lecciones, hacer posible la ceremonia de la lección, de la lectura pública. Por eso, tanto los profesores como los estudiantes son personas para las que el estudio no es una vocación particular, una actividad privada, sino una actividad pública, una actividad que se realiza en público. $Y$ una actividad que se realiza en relación a algo común. Y lo común es el texto en tanto que su lectura se separa de intereses particulares (de los intereses de individuos particulares, o de grupos sociales particulares, pero también de los intereses particulares de los mercados, o de los estados), se separa también de cualquier uso particular (en la esfera de la producción o de la reproducción), para convertirse en un asunto común, pero un común, repito, que tiene más que ve con comunismo que con comunicación. Lo que hace la Universidad es comunizar el saber, comunizar el libro, comunizar las materias de estudio, hacer del saber, del libro, de la materia de estudio, pero también de la verdad, e incluso me atrevería a decir, del mundo, algo común, algo público, algo que es de todos los que están concernidos, o interesados, por el saber, por el libro, por la materia de estudio, por la verdad, por el mundo.

10.

Hasta aquí la descripción del dispositivo universitario. $Y$ del lugar del estudio en el interior de ese dispositivo. Naturalmente, ese dispositivo, ese artefacto, esa curiosa composición de rituales, rutinas, espacios, tiempos, materialidades, subjetividades y formas de hacer, es un dispositivo capturado, a lo largo del tiempo, por distintos intereses. No hace mucho estuve en el Estudio General de los dominicos, en Valladolid. El edificio, muy hermoso, tiene en su frontispicio el árbol de la ciencia, cuya base, como saben, es la Teología. La Universidad al servicio de la fe. Pero después ese árbol fue cubierto por el escudo de los Reyes Católicos. La Universidad al servicio de la Corona, al servicio del Estado. Digamos que una misma estructura formal ha sido puesta al servicio de distintos amos. En ese extraordinario panfleto contra las bases educativas de la cultura moderna que lleva por título Sobre el porvenir de nuestras escuelas, Nietzsche describe la Universidad como una máquina acústica a la que los profesores se vinculan por la boca, en tanto que hablantes, y los estudiantes por el oído, como oyentes.

La cita, de la última conferencia, podría ser la siguiente: "El estudiante escucha (...). Con bastante frecuencia el estudiante escribe también, mientras escucha. Ésos son los momentos en que está unido al cordón umbilical de la universidad (...). Por su parte, el profesor habla a esos estudiantes que escuchan. Muchas veces el profesor lee mientras habla (...). Una sola boca que habla y muchísimos oídos, con un número menor de manos que escriben: tal es el aparato académico exterior, tal es la máquina cultural universitaria, puesta en funcionamiento" (NIETZSCHE, 2000, p. 149-150).

Revista Digital do LAV - Santa Maria - vol. 9, n. 2, p. 114 - 132. - mai./ago. 2016 ISSN 1983 - 7348 http://dx.doi.org/10.5902/1983734823516 
Los dispositivos de la enseñanza universitaria han sido, durante siglos, dispositivos sonoros. Y Nietzsche, que tenía el oído muy fino, supo escuchar el rumor inquietante de lo que se escondía detrás de la así llamada "libertad académica", de la así llamada "autonomía de profesores y alumnos", y detrás de la así llamada "democratización de la cultura y de las instituciones de cultura", de la así llamada "cultura generalizada": las voces gemelas del Estado y de la utilidad: "El profesor puede decir prácticamente lo que quiere, y el estudiante puede escuchar prácticamente lo que quiere: sólo que, detrás de esos dos grupos, a respetuosa distancia y con cierta actitud anhelante de espectador, está el Estado, para recordar de vez en cuando que él es el objetivo, el fin y la suma de ese extraño procedimiento consistente en hablar y en escuchar" (NIETZSCHE, 2000, p. 150).

Es como si las voces que sonaban en esa Universidad que Nietzsche todavía se esforzaba, en aquella época, por habitar, fueran voces cuyo origen y cuyo destino no es la boca o los oídos en que suenan y resuenan, sino algo que se esconde detrás del telón. En la Universidad es el Estado el que habla, el que determina lo que se dice y, sobre todo, el cómo se dice, y el que determina también lo que se escucha y el cómo se escucha. Desde luego, son los profesores los que hablan ( $y$ a veces leen mientras hablan) y son los estudiantes los que escuchan ( $y$ a veces escriben mientras escuchan). Los profesores son libres para decir lo que quieren. Los estudiantes también son libres: escogen lo que quieren escuchar, pueden taparse los oídos si no quieren escuchar, pueden negar la autoridad de lo que escuchan, pueden ser autónomos y críticos, como se dice ahora, en relación a lo que escuchan. Pero esas bocas y esos oídos han sido ya configurados según la lógica del Estado y según la lógica de la utilidad que son, en definitiva, la misma lógica.

11.

Pero lo que está pasando ahora no es sólo que el dispositivo universitario está siendo capturado por los poderes del presente (que ya no son los de la Iglesia, o los del Estado, sino los de nuevo capitalismo globalizado, ese que lo convierte todo en mercancía, ese que pone la Universidad al servicio de la producción y del consumo), sino que es el mismo dispositivo el que está desapareciendo. Mi tesis es que el dispositivo formal de la Universidad, y la idea misma del estudio, precisamente por lo que implicaban de tiempo libre, de espacio público, de sujetos no subordinados ni a la economía ni a la religión ni al estado, aún podía resistir a todos los intentos de captura. Precisamente por su desconexión. Pero si es el dispositivo mismo el que es arrasado, la Universidad ya no es Universidad, y el estudio ya no tiene sentido. Repasaré algunos signos de ese

Revista Digital do LAV - Santa Maria - vol. 9, n. 2, p. 114 - 132. - mai./ago. 2016 ISSN 1983 - 7348 http://dx.doi.org/10.5902/1983734823516 
arrasamiento. Y los dejaré sin desarrollar porque constituyen nuestra experiencia de todos los días.

Primero, la conversión de las aulas y de las bibliotecas en entornos de aprendizaje. O, dicho más radicalmente, la desaparición de la sala de aula y la desaparición de la biblioteca. Segundo, la cancelación del tiempo libre y su sustitución por el tiempo productivo, constituido por criterios de rentabilidad, de inversión. Tercero, la cancelación del espacio público y su sustitución por un espacio individualizado en el que cada uno está conectado a su terminal, en función de sus propios intereses, de sus propios talentos, de sus propias capacidades. De hecho, la sala de aula, que aún constituía una esfera pública, un espacio tridimensional centrado, se está convirtiendo en un espacio bidimensional. Cuarto, la cancelación de la materia común y su sustitución por una serie de contenidos, de paquetes de información, que tienen que ser apropiados individualmente.

Lo que se quiere es que ya no haya estudiosos ni estudiantes, es decir, personas que quieren estudiar, que no tienen intereses particulares, sino que están interesados en una materia de estudio y quieren exponerse a esa materia fuera de cualquier lógica de inversión, o de cálculo, o de rentabilidad, o de productividad. Los estudiantes se convierten en capital humano, y en receptores de contenidos, o procesadores de información. Lo que se quiere es que ya no haya maestros, profesores, scholars, personas que quieren estudiar y hacer de su estudio un asunto público, personas que aman una materia de estudio y quieren comunizarla, hacerla disponible, ponerla a disposición de todos. Los profesores, los maestros, se convierten en productores de contenidos, transmisores o comunicadores de contenidos, innovadores, gestores del aprendizaje de unos estudiantes que ya no son estudiantes sino aprendices. Lo que está acabando con la Universidad y con el estudio es su subordinación al dispositivo "profesionalización" (con lo que supone de subordinación al mercado de trabajo), al dispositivo "investigación" (completamente mercantilizado) y al dispositivo "aprendizaje" (completamente individualizado).

\section{Referencias}

AGAMBEN, Giorgio. "Idea del estudio", en Idea de la prosa. Buenos Aires: Adriana Hidalgo, 2014.

ARENDT, Hannah. "¿Dónde estamos cuando pensamos? En La vida del espíritu. Madrid: Centro de Estudios Constitucionales, 1984.

CALEY, David. Conversaciones con Iván Illich. Madrid: Enclave de libros, 2013.

Revista Digital do LAV - Santa Maria - vol. 9, n. 2, p. 114 - 132. - mai./ago. 2016 ISSN 1983 - 7348 http://dx.doi.org/10.5902/1983734823516 
ILLICH, Iván. En el viñedo del texto. Etología de la lectura: un comentario al 'Didascalion' de Hugo de San Víctor. México: FCE, 2002.

LORAUX, Nicole. La invención de Atenas. Historia de la oración fúnebre en la ciudad clásica. Buenos Aires: Katz, 2012.

MASSCHELEIN, Jan; SIMONS, Maarte. "The University: a public issue", en BARNETT, R. (Ed.) The future university. Ideas and possibilities. New York: Taylos and Francis, 2011. NIETZSCHE, Friedrich. Sobre el porvenir de nuestras escuelas. Barcelona: Tusquets, 2000.

SLOTERDIJK, Peter. Normas para el parque humano. Madrid: Siruela, 2000.

SLOTERDIJK, Peter. Muerte aparente en el pensar. Sobre la filosofía y la ciencia como ejercicio. Madrid: Siruela, 2013.

STIEGLER, Bernard. Prendre soin. De la jeunesse et des générations. Paris: Flammarion, 2008.

Professor de Filosofia da Educação na Universidade de Barcelona. É doutor em Pedagogia e realizou estudos de pós-doutorado no Instituto de Educação da Universidade de Londres e no Centro Michel Foucault da Sorbonne, em Paris.

Enviado em: 30 de maio de 2016.

Aprovado em: 01 de agosto de 2016.

Revista Digital do LAV - Santa Maria - vol. 9, n. 2, p. 114 - 132. - mai./ago. 2016 ISSN 1983 - 7348 http://dx.doi.org/10.5902/1983734823516 